\title{
Model based Controller Design for Conical Tank System
}

\author{
D.Angeline \\ Vijula, M.E., Ph.D \\ Associate \\ Professor, \\ Department of EIE, \\ Sri Ramakrishna \\ Engineering \\ College, \\ Coimbatore
}

\author{
K.Vivetha, \\ UG Student, \\ Department of EIE, \\ Sri Ramakrishna \\ Engineering \\ College, \\ Coimbatore
}

\author{
K.Gandhimathi, \\ UG Student, \\ Department of EIE, \\ Sri Ramakrishna \\ Engineering \\ College, \\ Coimbatore
}

\author{
T.Praveena, \\ UG Student, \\ Department of EIE, \\ Sri Ramakrishna \\ Engineering \\ College, \\ Coimbatore
}

\begin{abstract}
The control of liquid level is mandatory in process industries. But the control of nonlinear process is complex. Many process industries use conical tanks because of its non linear shape which contributes better drainage for solid mixtures, slurries and viscous liquids. So, level control of conical tank presents a challenging task due to its nonlinearity and constantly changing cross-section. The main objective is to implement the suitable controller design for conical tank system to maintain the desired level. In this paper it is proposed to obtain the mathematical modelling of a conical tank system and to design model based controller (Internal Model Control) for controlling the level in it. The controller will be simulated using MATLAB SIMULINK. By using the advanced control scheme it is expected to have better closed loop performance and robustness when compared to PID controller.
\end{abstract}

\section{Keywords}

Non Linear Process, Internal Model control, conical tank.

\section{INTRODUCTION}

Conical tank is non-linear in nature because of its varying cross sectional area. For industries using non linear processes the controller design is a challenging task, because majority of the control theory deals with linear process. Many industries use proportional controller (PI) and proportional integral derivative controller because of its simple structure and easy tuning [2]. They are perfect control for linear process. Tuning of the controller is setting the proportional, integral and derivative constant to get the best control of the process. The conical tank is highly non linear. But stability of the system may be affected [7]. So model based controller design is implemented to maintain the desired level [5], [6].

The proposed work's objective is to implement model based controller design which uses model of the process to calculate the controller setting, but the structure of the model has not been explicitly involved in the controller design. There are several alternative controller design methods that make more explicit use of a process model.

Model reference adaptive controller arises some stability problem during real time implementation [1]. One of the methods is internal model control (IMC). The model of the process is run in parallel with the actual process. The IMC design procedure is exactly same as the open loop control design procedure. Unlike, the open loop control the IMC structure compensates for disturbances and model uncertainty. The fuzzy control scheme can also be employed to stabilize the non-linearity [3].

The section two deals with the experimental setup of the conical tank system. The section three explains the mathematical modelling of the system. The section four deals with the PID controller. The servo and regulatory response is obtained for the conical tank. IMC based tuning is explained in the section five. The results are obtained and the comparison is done in the section six. The section seven gives the conclusion and future enhancements.

\section{EXPERIMENTAL SETUP}

The system used is a conical tank and is highly nonlinear due to the variation in area of cross section of the level system with height. The controlling variable is inflow rate of the tank. The controlled variable is level of the conical tank. Level sensor is used to sense the level in the process tank and fed into the signal conditioning unit which makes the required signal for further processing.

The process is interfaced with the personal computer using DAQ card. The personal computer acts as a controller. The output from the personal computer is fed to the drive circuit. The drive circuit consist of power electronic devices like SCR, TRIAC, etc. Then the control action can be taken by using the final control element. The controlling variable is inflow rate of the tank and thus the desired level can be maintained.

Specification of conical tank system

$\begin{array}{ll}\text { Height, } \mathrm{H} & : 70 \mathrm{~cm} \\ \text { Steady state value, h } & : 10 \mathrm{~cm} \\ \text { Bottom radius, } \mathrm{r} & : 2 \mathrm{~cm} \\ \text { Top radius, } \mathrm{R} & : 17.6 \mathrm{~cm} \\ \text { Material } & : \text { Stainless steel }\end{array}$




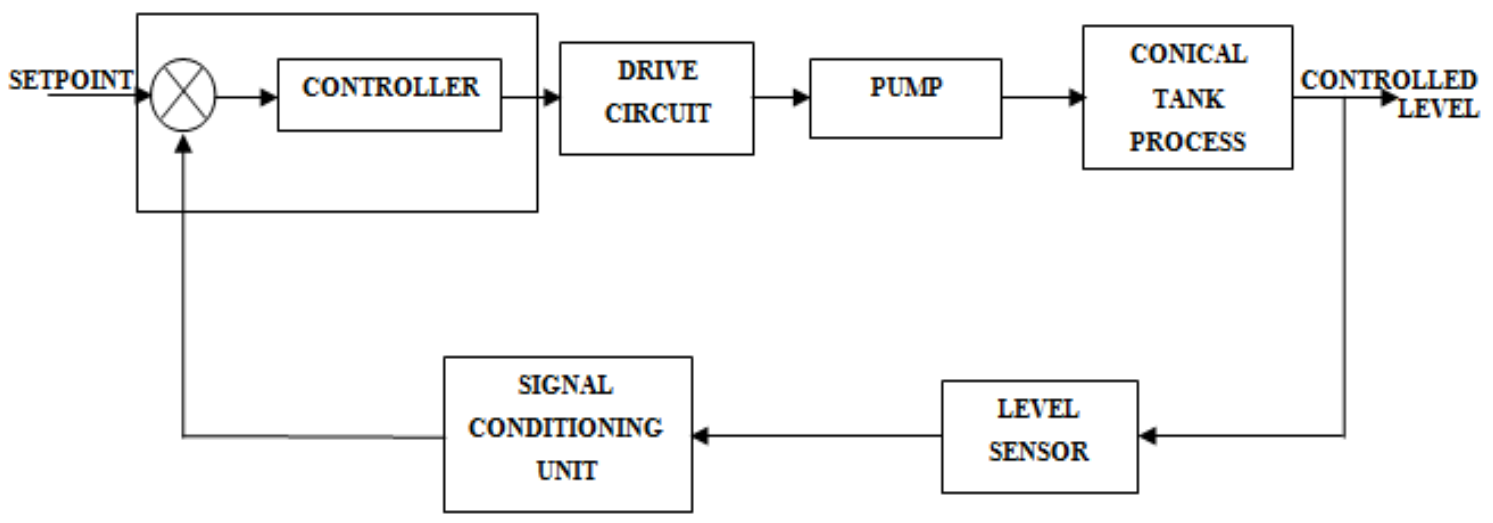

Fig 1: Block diagram of conical tank system

\section{MATHEMATICAL MODELLING}

The process considered here is the conical tank system as shown in figure. 2 in which liquid level is maintained at a constant rate by controlling the inflow of the tank Q.

\section{Q}

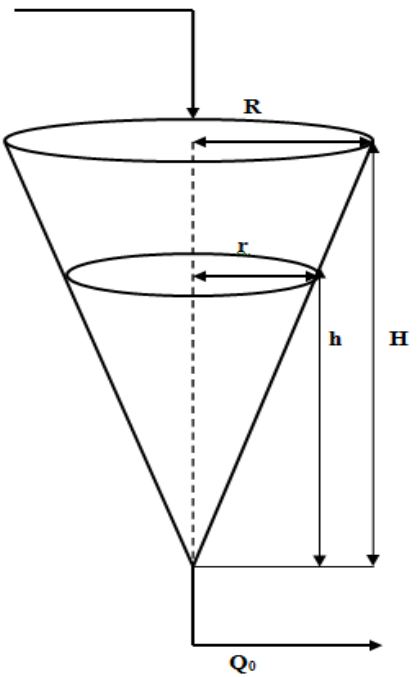

Fig2: Conical tank

Q Flow rate of the inlet stream

$\mathrm{Q}_{\mathrm{o}} \quad$ Flow rate of the outlet stream

$\mathrm{R} \quad$ Maximum radius of the conical tank

$\mathrm{r} \quad$ Radius of the conical tank at steady state

$\mathrm{H} \quad$ Maximum height of the conical tank

$\mathrm{h} \quad$ Height of the conical tank at steady state

The mathematical modelling of the system should be obtained. Using the process parameters.

According to mass balaance equation, Accumulation $=$ Input - Output

$$
\begin{aligned}
& A \frac{d h}{d t}=Q-Q_{0} \\
& \text { Area, } A=\pi r^{2}=\pi\left(\frac{R h}{H}\right)^{2}
\end{aligned}
$$

So that the tank model becomes,

$$
\frac{\mathrm{dh}}{\mathrm{dt}}=\frac{\alpha \mathrm{Q}}{\mathrm{h}^{2}}-\beta \mathrm{h}^{-3 / 2}
$$

Where $\alpha$ and $\beta$ are parameters defined by,

$$
\begin{aligned}
& \alpha=1 / \pi\left(\frac{\mathrm{H}}{\mathrm{R}}\right)^{2} \\
& \beta=\mathrm{c} \alpha
\end{aligned}
$$

Here, $\mathrm{Q}$ is the inlet flow rate, the manipulated variable. This process model has two types of nonlinear functions: $\mathrm{Qh}^{-2}$, a product of two functions, and $\mathrm{h}^{-3 / 2}$. These two functions have to be linearised. Linearization is the process by which a nonlinear system is approximated to a linear process model.

The most popular technique for obtaining the linear approximation is based on Taylor series expansions of the nonlinear aspects of the process model. The process model has two types of nonlinear functions: $\mathrm{Qh}^{-2}$, a product of two functions and $\mathrm{h}^{-3 / 2}$.

The linearization of $\mathrm{f}(\mathrm{h}, \mathrm{Q})=\mathrm{Qh}^{-2}$ proceeds as follows,

$$
\begin{aligned}
f(h, Q)=f\left(h_{s}, Q_{s}\right)+\frac{\partial f\left(h-h_{s}\right)}{\partial h}+\frac{\partial f\left(Q-Q_{s}\right)}{\partial Q} \\
+ \text { higher order terms }
\end{aligned}
$$

Ignore the higher order terms,

$$
h^{-3 / 2}=h_{s}^{-3 / 2}-3 / 2 h_{s}^{-\frac{5}{2}}\left(h-h_{s}\right)
$$

Under steady state condition, $\alpha Q_{s}=\beta h_{s}^{1 / 2}$. Now introduce the variables $\mathrm{y}=\left(\mathrm{h}-\mathrm{h}_{\mathrm{s}}\right)$ and $\mathrm{u}=\left(\mathrm{Q}-\mathrm{Q}_{\mathrm{s}}\right)$.

The approximate linear model is obtained as,

$$
\tau\left(\frac{d y}{d t}\right)+y=K u
$$


Where the steady-state gain, and time constant associated with this approximate linear model, are given by,

$$
\begin{aligned}
& \qquad \mathrm{K}=\frac{2 \alpha}{\beta} h_{\mathrm{s}}^{\frac{1}{2}}=\frac{2}{\mathrm{c}} \mathrm{h}_{\mathrm{s}}^{\frac{1}{2}} \\
& \text { And } \begin{aligned}
\tau & =\frac{2}{\beta} \mathrm{h}_{\mathrm{s}}^{5 / 2}
\end{aligned}
\end{aligned}
$$

Applying the values for all the parameters and taking Laplace transform, the conical tank transfer function is obtained.Once the transfer function is obtained,then the controller can be designed for the conical tank process. process

The system transfer function is obtained as first order

$$
\mathrm{G}_{\mathrm{m}}(\mathrm{s})=\frac{3.184}{62.81 \mathrm{~s}+1}
$$

\section{PID CONTROLLER}

A proportional-integral-derivative controller (PID controller) is a generic control loop feedback mechanism (controller) widely used in many control systems.

A PID controller calculates an error value as the difference between a measured process variable and a desired set point. The controller attempts to minimize the error by adjusting the process control inputs. The PID controller is simple and robust and hence widely used in most of the process industries.

The controller parameters can be tuned using Cohen and Coon method or Ziegler Nichol's method [4]. Cohen and Coon method is commonly referred to as open loop response method for tuning the parameters of conventional controllers.

Once the open loop response is obtained the required values are noted. In order to obtain the required gain values of the PID controller the following tabulation can be used.

Table 1: Cohen and Coon tuning formulae

\begin{tabular}{|l|l|l|l|}
\hline Type & $\mathrm{K}_{\mathrm{p}}$ & $\mathrm{T}_{\mathrm{i}}$ & $\mathrm{T}_{\mathrm{d}}$ \\
\hline $\mathrm{P}$ & $\left(\frac{\tau}{K t_{d}}\right)\left(1+\frac{t_{d}}{3 \tau}\right)$ & - & - \\
\hline $\mathrm{PI}$ & $\left(\frac{\tau}{K t_{d}}\right)\left(0.9+\frac{t_{d}}{12 \tau}\right)$ & $t_{d}\left(\frac{30+\frac{3 t_{d}}{\tau}}{9+\frac{20 t_{d}}{\tau}}\right)$ & - \\
\hline PID & $\left(\frac{\tau}{K t_{d}}\right)\left(\frac{4}{3}+\frac{t_{d}}{4 \tau}\right)$ & $t_{d}\left(\frac{32+\frac{6 t_{d}}{\tau}}{13+\frac{8 t_{d}}{\tau}}\right)$ & $\mathrm{t}_{\mathrm{d}}\left(\frac{4}{11+\frac{2 \mathrm{t}_{d}}{\tau}}\right)$ \\
\hline
\end{tabular}

Using the above formulae the gain values can be obtained. The proportional control will make the system to be stable but there exists an offset error. But increasing the proportional gain value makes the system unstable and the response oscillates continuously.

Integral control is used to eliminate the offset. It corrects the offset overtime by shifting the proportional band. If the reset time is too small, the response oscillates continuously. If the reset time is too long, the system will take long time to settle out.
Derivate action is to make the process variable to settle quickly after the disturbance. This can be mainly used for slow process. The derivative control also reduces the peak overshoot.

Therefore, Proportional Integral Derivative (PID) controller is used to obtain the closed loop response of the conical tank system. The system transfer function is

$$
\mathrm{G}_{\mathrm{m}}(\mathrm{s})=\frac{3.184}{62.81 \mathrm{~s}+1}
$$

Using this transfer function, the closed loop response is obtained.

\section{INTERNAL MODEL CONTROL}

The basic idea of IMC is to use a model of the open loop process transfer function in such a way that the selection of the specified closed loop response yields a physically realisable controller. IMCs are much easier to tune than other controllers in a standard feedback control structure.

The internal model principle states that control can be achieved only if the control system encapsulates, either implicitly or explicitly some representation of the process to be controlled. Process model embedded in the controller.

This method is very effective for utilising process model as a feedback control. The process model is directly used and hence reduces the on-line computation. Process model that receives the same manipulated variable signal as the actual process. Then subtract the difference between the process output (actually measured) and the process model output (model predicted) to determine the model error. The disturbances entering into the system should be taken in consideration.

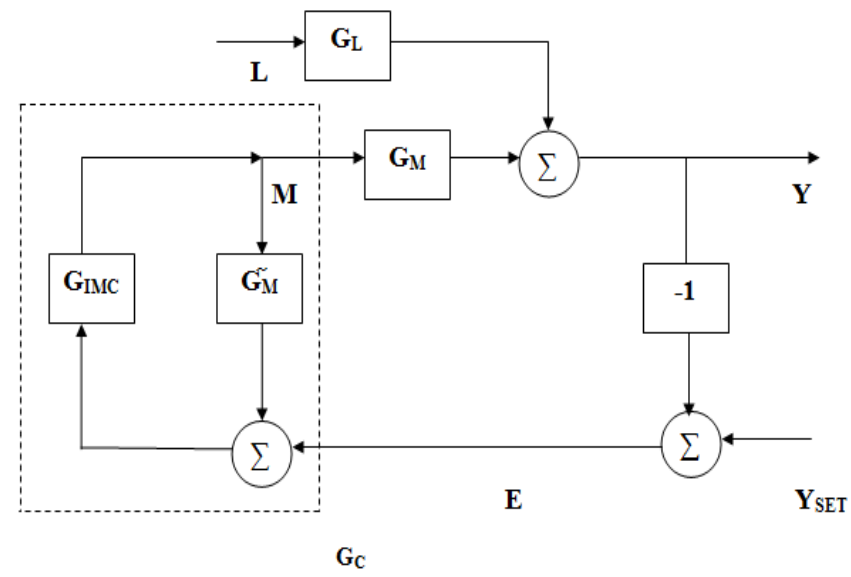

Fig 3: Basic structure of Internal Model Control

The open loop transfer function of the process is

$$
G_{m}(s)=\frac{3.184}{62.81 s+1}
$$

The IMC controller transfer function is

$$
G_{I M C}(s)=\frac{1}{G_{m}(s)} S(s)
$$

The best way to select the closed loop servo transfer function $\mathrm{S}(\mathrm{s})$ to make physically realizable is

$$
\begin{aligned}
& S(s)=\frac{1}{T_{c} s+1}=\frac{1}{5 s+1} \\
& \mathrm{~S}(\mathrm{~s})=\frac{\mathrm{Y}(\mathrm{s})}{\mathrm{Y}^{\mathrm{set}}(\mathrm{s})}=\frac{\mathrm{G}_{\mathrm{m}}(\mathrm{s}) \mathrm{G}_{\mathrm{c}}(\mathrm{s})}{1+\mathrm{G}_{\mathrm{m}}(\mathrm{s}) \mathrm{G}_{\mathrm{c}}(\mathrm{s})}
\end{aligned}
$$


$\frac{Y(s)}{Y^{s e t}(s)}=\frac{1}{T_{C} s+1}=\frac{1}{5 s+1}$

By solving, the feedback controller, the IMC controller equation can be obtained.

$$
\mathrm{G}_{\mathrm{c}}(\mathrm{s})=\frac{62.81 \mathrm{~s}+1}{15.92 \mathrm{~s}}
$$

\section{SIMULATION RESULTS}

The closed loop response is obtained. Both the servo and regulator operations are obtained. In the servo operation only setpoint tracking is done. In the regulator operation, the disturbances can be corrected automatically and desired level is obtained.

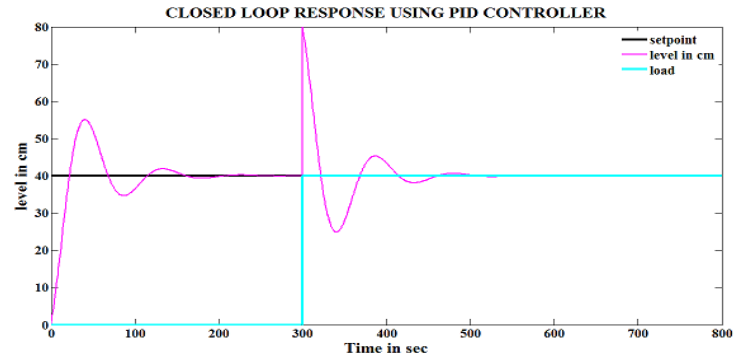

Fig 4: Simulation result of closed loop response

The Internal Model Control is used to obtain the closed loop response. Both servo and regulator operations are obtained as shown in the figure 5 .

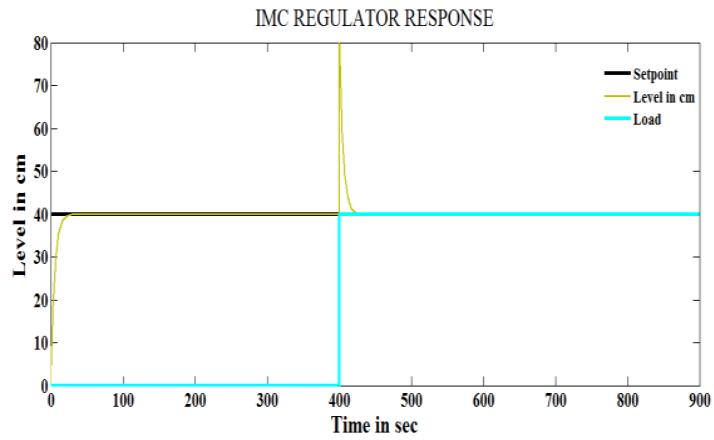

Fig 5: Simulation Result of Internal Control Model

The PID controller is normally used for all the systems. Since it is a non-linear system Internal Model Control is used to obtain better performance. To Compare the Controller action various parameters such as rise time, peak time, peak overshoot and settling time are taken.

Table 2: Comparative results of different controllers for conical tank system

\begin{tabular}{|l|l|l|l|l|}
\hline $\begin{array}{l}\text { controller } \\
\text { type }\end{array}$ & $\begin{array}{l}\text { Rise } \\
\text { Time } \\
\text { (sec) }\end{array}$ & $\begin{array}{l}\text { Peak } \\
\text { Time } \\
(\mathrm{sec})\end{array}$ & $\begin{array}{l}\text { Peak } \\
\text { overshoot }\end{array}$ & $\begin{array}{l}\text { Settling } \\
\text { time } \\
(\text { sec })\end{array}$ \\
\hline PID & 30 & 50 & $30 \%$ & 300 \\
\hline $\begin{array}{l}\text { IMC } \\
\text { (Tuning) }\end{array}$ & 22 & - & - & 30 \\
\hline
\end{tabular}

As shown in table. 2 the peak overshoot is reduced in IMC when compared to the PID controller. The settling time is also reduced in IMC which means it gives the faster response.

\section{CONCLUSION AND FUTURE ENHANCEMENTS}

The controlling of nonlinear process is a challenging task. The Model Based controller is designed in such a way that the system is robust and physically realizable. But due to the presence of dead time, the performance of the system may be affected. Using advanced control schemes such as Model Predictive control better performance and robustness can be obtained.

\section{REFERENCES}

[1] Anna Joseph and Samson Isaac, J. (2013) 'Real Time Implementation of Model Reference Adaptive Controller for a Conical Tank', proceedings of International Journal on Theoretical and Applied Research in Mechanical Engineering, Vol.2, No.1, pp 57-62.

[2] Abhishek Sharma and Nithya Venkatesan (2013) 'Comparing PI controller Performance for Non Linear Process Model', proceedings of International Journal of Engineering Trends and Technology, Vol.4, No.3, pp. 242-245

[3] Sowmyal, P., Srivignesh, N., Sivakumaran, N. and Balasubramanian, G. (2012) 'A Fuzzy Control Scheme for Nonlinear Process', IEEE transactions on International Conference On Advanced Engineering Science and Management , pp. 683-687.

[4] Marshiana, D. and Thirusakthimurugan, P. (2012) 'Design of Ziegler Nichols Tuning controller for a Nonlinear System', proceedings of International Conference on Computing and Control Engineering, pp.121-124.

[5] Warier, S.R., Venkatesh, S. (2012) 'Design of controllers based on MPC for a conical tank system', proceedings of Advances in Engineering, Science and Management, pp. 309-313.

[6] Venkatesan, N. and Anantharaman, N.(2012) 'Controller design based on Model Predictive Control for a nonlinear process', proceedings of Mechatronics and its Applications, Vol.4 , pp. $1-6$

[7] Anand, S., Aswin, V. and Kumar, S.R.(2011) 'Simple tuned adaptive PI controller for conical tank process', Recent Advancements in Electrical, Electronics and Control Engineering, pp. 263 - 267.

[8] Nithya, S., Sivakumaran, N., Balasubramanian, T. and Anantharaman, N. (2008) 'Model based controller design for a spherical tank process in real time', proceedings of International Journal of Simulation, Systems, Science and Technology, Vol. 9, No. A4, pp 247-252. 